\title{
Estratégias de Comprometimento e Planos de Participação nos Lucros: Tendências Recentes
}

\author{
Grace Vieira Becker \\ Roberto Lima Ruas
}

\section{RESUMO}

Num ambiente em que o perfil do trabalho implica envolvimento do trabalhador, a fim de que tome iniciativas do tipo controle da qualidade, identificação de defeitos, participação em grupos de melhorias e outras formas de ação que requerem disposição para participar, ressalta-se a questão do comprometimento. Na busca de princípios e práticas de gestão que contemplem esta nova "exigência", os Planos de Participação nos Lucros e Resultados (PLR) no Brasil vem paulatinamente conquistando espaços, dada a crescente valorização de incentivos monetários para amenizar as condições precárias da nossa classe trabalhadora. Como ainda são raros os estudos sobre o assunto no nosso país, este trabalho apresenta resultados de uma pesquisa realizada em quatro indústrias no Rio Grande do Sul, sobre suas experiências na prática de Planos de PLR. A metodologia utilizada foi de natureza qualitativa através de estudo exploratório-descritivo. As entrevistas procuraram captar como as empresas estudadas estão utilizando esta estratégia de gestão de recursos humanos e mostrar os reflexos desta estratégia sobre os trabalhadores. Nosso objetivo se orienta por uma tentativa de identificar tendências, características e sistemáticas desses Planos, mesmo porque seria prematuro pretender conclusões definitivas acerca da difusão dessa estratégia para o caso brasileiro.

Palavras-chaves: incentivos monetários, participação nos lucros, participação nos resultados, comprometimento.

\begin{abstract}
:
In an environment in which the work profile implies the worker's involvement in the process of taking initiatives such as quality control, defects identification, participation of team groups and other ways of performance requiring disposition to participate, subject of commitment stands out. Looking for management principles and practices absorbing this new "requirement", the Profit or Gain Sharing Plans in Brazil are gradually conquering their space because of the increasing valorization of monetary incentives to minimize the delicate conditions of Brazilian working class. Due to the small amount of studies on this subject in our country, this paper presents results of a research led in four industries in the State of Rio Grande do Sul on their experiences in the practice of PGSP. The methodology employed has been of a qualitative kind, using an exploratorydescriptive study. The interviews aimed observing how the studied companies are employing this ruman resources management strategy and to show its reflexes on their workers. Our objective is an attempt to identify trends, characteristics and structures concerning to these plans, once it would be premature to seek more definitive conclusions on the diffusion of this strategy for the Brazilian case.
\end{abstract}

Key words: monetary incentives, profit sharing, gain sharing, commitment. 


\section{Novas formas de Gestão do Trabalho, A Questão do Comprometimento e os Planos de Participação nos lucros}

Uma das principais mudanças características do novo paradigma produtivo se refere à gestão do trabalho. À medida que o perfil do trabalho exigido implica envolvimento do trabalhador, a fim de que tome iniciativas do tipo controle da qualidade, identificação de defeitos, participação em grupos de melhorias e outras formas de ação que requerem disposição para participar, a gestão dos trabalhadores sofre modificações profundas (Ruas, 1995). Neste ambiente, a questão do comprometimento dos trabalhadores passa a ter um papel fundamental. Dentre as diversas formas de buscar vínculos de comprometimento com os funcionários, os Planos de Participação nos Lucros ou Resultados (PLR) em muitos países têm constituído uma estratégia de destaque. No Brasil, apesar das iniciativas pioneiras de algumas empresas, é somente com as sucessivas publicações da Medida Provisória, desde o final do ano de 1994, que se vem regulamentando esse tipo de política: os Programas de Participação nos Lucros passam a ter certa prioridade em termos de estratégia de comprometimento.

Neste sentido, a Medida Provisória tem como principal objetivo,

\footnotetext{
"regular a participação dos trabalhadores nos lucros ou resultados como instrumento de integração entre capital e trabalho e como incentivo à produtividade, nos termos do Art. 7, XI, da Constituição" (Medida Provisória N. 1539 - 30, de 11 de abril de 1997).
}

O que de fato tem atraído os empresários à adoção deste sistema é a desvinculação do valor a ser distribuído à remuneração do empregado, ou seja, a participação não substitui ou complementa a remuneração devida pela empresa ao trabalhador, e também não considera este valor como base para cálculo de encargos trabalhistas e previdenciários. No Rio Grande do Sul, por exemplo, pesquisa recente, realizada entre 150 empresas industriais, revelou que 69 delas $(45,8 \%)$ estão implementando ou já implementaram este tipo de programa (SEBRAE/FIERGS/ PPGA, 1997) $)^{(1)}$.

Apesar da explosão de artigos na imprensa, principalmente em 1995, sobre a repercussão da Medida Provisória nas empresas no momento, são ainda raros os estudos e pesquisas acerca das formas principais deste tipo de programa no Bra- 
sil. Por isso, na expectativa de tornar mais visível algumas das principais características dos Programas de PLR, apresentaremos os resultados de estudo de caso, que envolvem quatro empresas industriais do Rio Grande do Sul, que vêm adotando esse tipo de programa. A empresa Alpha atua no segmento de equipamentos eletrônicos, a empresa Beta na indústria gráfica e de embalagens e as empresas Gama e Delta atuam no setor metal-mecânico, mais precisamente nos ramos de transportes e implementos agrícolas, respectivamente.

A metodologia utilizada foi de natureza qualitativa por meio de estudo exploratório-descritivo. A pesquisa de campo dividiu-se em duas etapas. A primeira etapa consistiu na aplicação de entrevistas semi-estruturadas para a gerência e supervisão, com o objetivo de captar detalhadamente como as empresas estão utilizando esta estratégia de gestão de recursos humanos. Já a segunda parte procurou mostrar os reflexos desta estratégia sobre os trabalhadores, através da análise de seus próprios depoimentos, evidenciando suas percepções e posturas em face da utilização deste Plano.

Considerada a escassa documentação teórica e empírica acerca do tema, especialmente no que concerne à realidade da empresa brasileira, nosso objetivo se orienta por uma tentativa de identificar tendências, características e sistemáticas desses programas, mesmo porque seria prematuro e irresponsável pretender conclusões mais definitivas acerca da difusão dessa estratégia para o caso brasileiro.

\section{Programas de Participaçāo: Um Debate Preliminar - Lucros ou Resultados}

Por nos situarmos nos primórdios do debate acerca do tema "Participação nos Lucros ou Resultados", algumas questões básicas ainda têm sido intensamente discutidas. É o caso, por exemplo, da escolha da referência utilizada para a distribuição dos benefícios para este tipo de programa.

Em outras palavras, ao conceber um Programa de Participação nos Lucros ou Resultados, é preciso definir qual será a medida de desempenho a ser tomada como referência - se a margem de lucro propriamente dita na forma de um resultado contábil ao final do exercício, ou se outras medidas de desempenho, tais como índices de produtividade, índices de qualidade, taxas de absenteísmo ou outros indicadores semelhantes. Nessa segunda configuração, diz-se que a referência para o Programa de Participação são alguns resultados previamente definidos como parâmetros. 
Como vimos, as duas principais referências para esse tipo de programa são Participação nos Lucros - PL (Profit sharing) ou Participação nos Resultados PR (Gain sharing). A chamada Participação nos Lucros é aquela em que o valor a ser distribuído é proporcional ao volume de lucros alcançados pela empresa em determinado tempo. Assim, nesse tipo de programa, a concessão de benefícios está diretamente relacionada à lucratividade da empresa, independentemente dos resultados individuais ou grupais dos trabalhadores nas suas próprias atividades.

Já no sistema de Participação com base nos Resultados, a concessão desse benefício está associada a resultados atingidos, não necessariamente contábeis, que a empresa espera alcançar e podem apresentar-se de várias formas, de metas de qualidade e produtividade, até índices de rotatividade ou de integração da equipe de trabalho. A peculiaridade dos Planos baseados em Resultados é de permitir à empresa certo nível de flexibilidade nos indicadores que são focalizados através dele, privilegiando aspectos diferentes simultaneamente, ou alternando-os sucessivamente, segundo os interesses da direção. O plano de Participação com base em Resultados permite, portanto, que a empresa o direcione para o atingimento de suas necessidades.

Considerada a pequena experiência das empresas brasileiras nesse campo, seria arriscado defender as vantagens de uma ou outra dessas alternativas de referência para esse tipo de programa; mas não há como não perceber algumas condições mais evidentes. No Gain sharing, por exemplo, há mais visibilidade na relação entre o desempenho dos trabalhadores e os indicadores que se quer atingir. Essa situação é flagrante para os casos de indicadores de produtividade de grupos, por exemplo, ou de taxas de absenteísmo.

Já para o caso do sistema de Participação nos Lucros esta relação entre desempenho e lucratividade não é tão bem percebida entre os trabalhadores. De fato, "a lucratividade nem sempre está relacionada ao desempenho do funcionário ou grupo" (Chiavenato, 1994, p. 228). A Participação nos Lucros apresenta-se mais condicionada a fatores externos à organização (sazonalidade dos produtos, política governamental, situação econômica do país, aplicação de recursos financeiros) do que à Participação nos Resultados. Davis e Newstrom (1992, p.108) ilustram essa situação, quando abordam algumas das dificuldades; quando a referência para esse tipo de programa está calcada apenas na obtenção de volumes determinados de lucros; quando afirmam que "condições de mercado desfavoráveis podem anular o trabalho dedicado de um empregado". Ao não estabelecer uma relação mais direta de causa e efeito, perde-se o sentido do Plano, que é o de envolver os funcionários no atingimento de melhores resultados, sejam contábeis ou não.

Neste sentido, pesquisas recentes (Zero Hora, 1994(2); Zylberstajn, 1996 $6^{(3)}$ ) afir- 
mam que é a Participação nos Resultados a de mais fácil entendimento, porque, apesar de envolver alguns parâmetros, estes são bem mais acessíveis do que a compreensão dos dados contábeis da empresa. Tal argumentação baseia-se no fato de que as organizações, pelo menos no Brasil, parecem não sentirem-se "muito à vontade" para abrir sua contabilidade aos funcionários ou em alguns casos aos sindicatos. Assim, a empresa correria o risco de ter sua contabilidade examinada detalhadamente; sendo o valor da distribuição afetado unicamente pelo lucro, espera-se que este seja alvo de controle permanente dos beneficiados pelo Plano (Zylberstajn, 1996).

É certo que gestores competentes podem extrair desta aparente desvantagem uma abordagem mais ampla, à medida que a própria relação com indicadores de lucratividade, que são relacionados a fatores externos, pode proporcionar aos funcionários uma visão mais abrangente do negócio da empresa e da forma de como ela se relaciona com o mercado. Além disso, outra vantagem atribuída ao sistema Profit Sharing é a de que o lucro é um indicador único, fácil de ser medido, dispensando, desta maneira, o uso de fórmulas para o cálculo da participação, e conseqüentemente facilitando o entendimento do Plano pelos funcionários (Coopers e Lybrand, 1996). Contrariamente ao argumento de que as margens de lucro constituem um segredo "a sete chaves" das empresas, pode-se citar pesquisa realizada por uma empresa de advocacia de Porto Alegre: mediante consulta a 80 empresários, constatou que $61,90 \%$ dos entrevistados considerava que a abertura da contabilidade não se revelava um fator impeditivo à adoção de Planos de Participação nos Lucros (Revista Comércio e Consumo, 1995).

Nesta controvérsia acerca das vantagens de um e outro sistema, as pesquisas têm confirmado certa predominância dos sistemas com base em resultados ${ }^{(4)} \mathrm{e}$ uma tendência à adoção de sistemas mistos, sendo este último uma combinação dos dois, ou seja, embora os requisitos para a distribuição dos benefícios de participação estejam baseados na obtenção de resultados específicos (índices de produtividade, qualidade etc), a condição para a distribuição desses resultados está associada a taxas de lucratividade pré-estabelecidas. Em outras palavras, mesmo que alguns dos resultados pretendidos sejam atingidos, o fato de a empresa não atingir padrões de lucratividade, considerados adequados, implica a não distribuição dos benefícios de participação.

Essa relação entre resultados específicos e lucratividade parece constituir uma forma amadurecida de tratar esse tipo de Programa de Participação: para Zylberstajn (1996), autor da Pesquisa UP DATE, "o lucro é um indicador definitivo do negócio. Nesse sentido, é ilógico distribuir resultados quando a empresa opera no vermelho". Entretanto o próprio autor afirma mais adiante que "é recomendável começar com indicadores de resultados, assumindo o risco de distribuí- 
los em épocas de prejuízo" (Zylberstajn, 1996). Neste caso, o grau de confiança e credibilidade fala mais alto, contribuindo para que os funcionários tenham compreensão do verdadeiro significado da palavra comprometimento.

No caso específico do estudo de caso que adotamos como base empírica de reflexão, a posição das quatro empresas pesquisadas pode ser sintetizada no Quadro 1 a seguir.

Como se observa pelo Quadro 1, em seus Programas de Participação, as empresas pesquisadas privilegiam a participação nos Resultados como referência principal para a distribuição de benefícios. Entretanto todas elas condicionam a bonificação pelos resultados obtidos a uma determinada margem de lucro no final do exercício, o que coloca esses programas numa ótica de programas de caráter misto.

Por outro lado, as empresas podem modificar as diretrizes desses programas. É o caso da empresa Delta, que desde 1993 vinha adotando um Plano de Participação centrado nos Lucros, mas que no final do ano passado, percebendo a necessidade de direcionar esforços no sentido de aumentar a produção de determinado produto e de reduzir as taxas de absenteísmo, começou a praticar também a Participação nos Resultados, com foco nestas questões. O caso da empresa Delta ilustra a crescente utilização de Planos Mistos de Participação.

\section{Condiçóes para o sucesso de um Programa de Participação em LuCros e Resultados}

Dentre as diversas razões para uma empresa tomar a iniciativa de implantar um programa desse tipo, destaca-se, com certeza, a busca de uma relação mais harmônica entre empresa e trabalhadores, com formas de motivação mais objetivas para o trabalhador, tendo em vista, especialmente, os novos desafios da atividade produtiva. Assim, com o foco neste objetivo, a concepção desses programas tem destacado algumas características consideradas fundamentais para seu êxito. Dentre as empresas pesquisadas, por exemplo, os principais requisitos e condições observados na concepção e na implementação dos Programas de Participação nos Lucros e Resultados foram os seguintes:

- Envolvimento/Comprometimento dos Funcionários: a necessidade de envolver e comprometer os funcionários em face das metas da empresa e do seu trabalho;

- Flexibilidade: configuração que permita adequar o Programa de Participação 


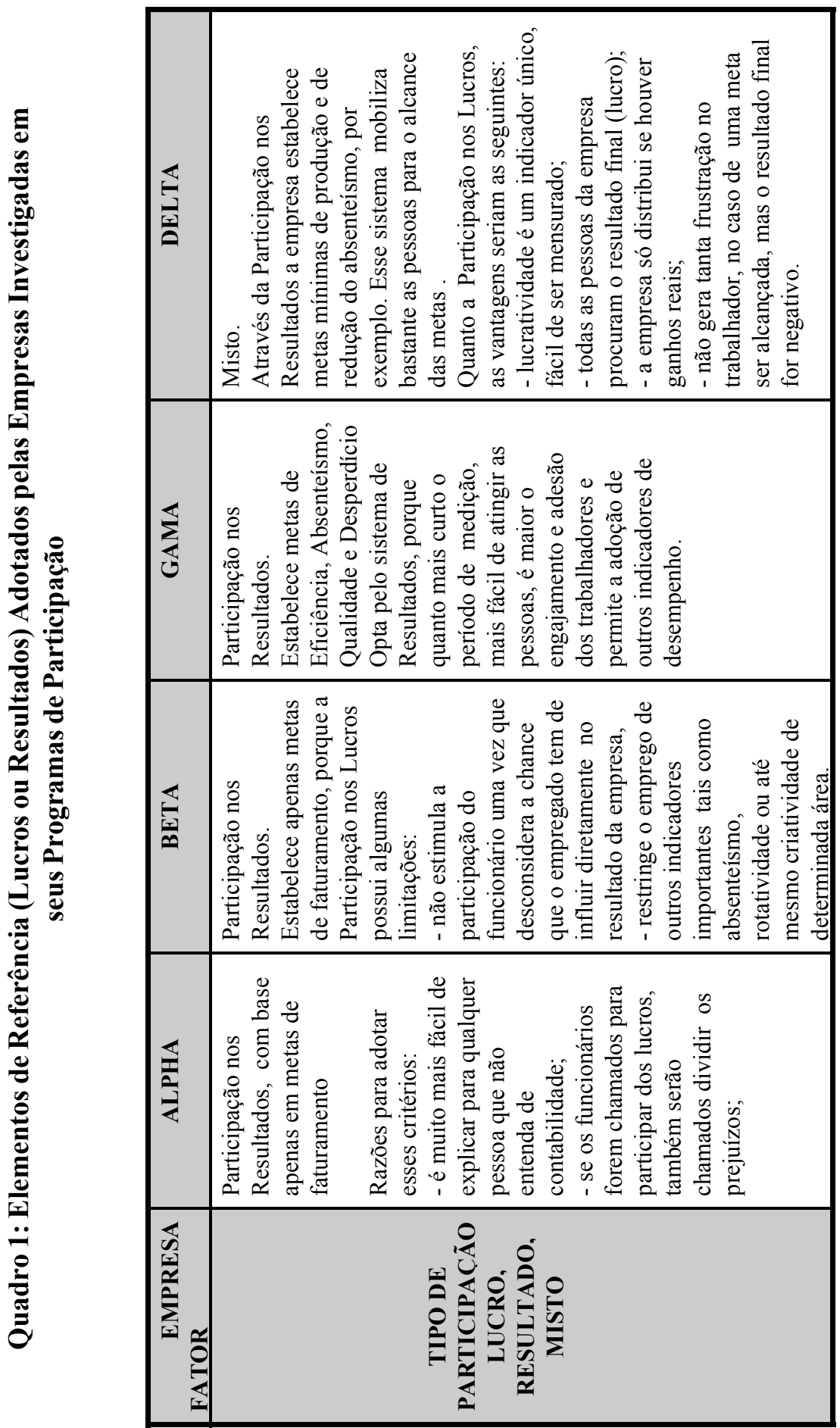


a mudanças de necessidades e interesses da empresa. Em outras palavras, o programa não deveria constituir "camisa de força" para a empresa. Neste ambiente, é possível incluir ou substituir indicadores e parâmetros, dependendo de novas urgências da empresa;

- Simplicidade e Objetividade das Regras: modelo que possa ser entendido por todas as pessoas da empresa;

- Transparência: acesso de todos às normas e regras do programa;

- Segurança em relação à transparência: ao mesmo tempo as regras do programa devem estar relacionadas a um tipo de documento ou informação que não coloque em risco aquelas informações consideradas estratégicas ou privadas acerca da empresa;

- Coerência: as normas do programa devem obedecer a critérios de coerência, de maneira que as bonificações obtidas pelo atingimento de resultados parciais estejam subordinadas a resultados contábeis positivos, isto é, não adianta obter resultados parciais, se o desempenho global da empresa não for positivo;

- Abrangência: o modelo deve atingir o maior número de pessoas da empresa.

Com base na configuração dos elementos acima, os quais, em última análise, representam os aspectos definidos pelas empresas como norteadores de seus Programas de Participação em Lucros e Resultados, passamos à análise das características principais desses programas, confrontando, quando possível, as práticas e normas dos programas com a opinião dos trabalhadores.

\section{Caracteristicas Básicas dos Programas de Participação em LUCROS: UMA EXPERIENCIA EM CONSTRUÇÃo}

\section{Requisitos ou Condições para a Distribuição da Bonificação por Lucros ou Resultados}

Requisitos ou condições para a distribuição são parâmetros que precisam ser atingidos para que a distribuição ocorra, segundo as metas previamente estabelecidas. É o caso, por exemplo, da obtenção de incrementos de produtividade até um índice desejado. Neste sentido, nossa pesquisa revela que as empresas Alpha, Beta e Gama, apesar de optarem pela Participação nos Resultados, condicionaram a distribuição ao atingimento de uma meta contábil, ou seja, de um determinado lucro (denominado pelas empresas de remuneração de capital). O 
fato de submeter a distribuição ao atingimento de uma lucratividade mínima nos remete a questão da Coerência, a qual condiciona a premiação à obtenção de uma margem de lucro determinada. Já a empresa Delta, assume totalmente este risco, uma vez que os dois tipos de participação utilizados funcionam independentes.

Por outro lado, a pesquisa mostra que algumas vantagens do sistema de Participação nos Resultados ainda não são muito bem exploradas. A empresa Gama é a única que apresenta uma diversidade de metas, criando seu próprio "pacote" de indicadores. Além do atingimento de metas contábeis (lucro), o alcance de metas de Eficiência, Qualidade, Desperdício e Absenteísmo também fazem parte da rotina diária dos funcionários da empresa Gama.

Já a empresa Delta tem direcionado seu Programa de Participação nos Resultados exclusivamente para metas de produção; as empresas Alpha e Beta apenas para metas contábeis.

O quadro a seguir resume os requisitos e condições para a distribuição em cada uma das empresas pesquisadas:

\section{Quadro 2: Requisitos ou Condições para a Distribuição da Bonificação por Lucros ou Resultados adotados pelas empresas investigadas em seus Programas de Participação}

\begin{tabular}{|c|l|l|l|l|}
\hline $\begin{array}{c}\text { EMPRESA } \\
\text { FATOR }\end{array}$ & \multicolumn{1}{c|}{ ALPHA } & \multicolumn{1}{c|}{ BETA } & \multicolumn{1}{c|}{ GAMA } & \multicolumn{1}{c|}{ DELTA } \\
\hline $\begin{array}{c}\text { CONDIÇÕES } \\
\text { PARA A } \\
\text { DISTRIBUIC̃̃o }\end{array}$ & $\begin{array}{l}\text { O faturamento } \\
\text { ultrapassar o } \\
\text { ponto de } \\
\text { equilíbrio da } \\
\text { empresa (custos } \\
\text { mais remuneração } \\
\text { do capital) }\end{array}$ & $\begin{array}{l}\text { A Margem de } \\
\text { Contribuição ser } \\
\text { superior ao } \\
\text { somatório dos } \\
\text { custos Fixos com } \\
\text { a Remuneração } \\
\text { do Capital. }\end{array}$ & $\begin{array}{l}\text { Apresentar Lucro Líquido } \\
\text { Contábil no semestre de } \\
\text { competência. } \\
\text { Indicadores: Eficiência, } \\
\text { Absenteísmo, Qualidade } \\
\text { e Desperdício }\end{array}$ & $\begin{array}{l}\text { Participação nos } \\
\text { Lucros: atingir um } \\
\text { patamar mínimo de } \\
\text { Lucro. } \\
\text { Participação nos } \\
\text { Resultados: } \\
\text { atingir meta mínima } \\
\text { de produção }\end{array}$ \\
\hline
\end{tabular}

\section{Definiçăo das Parcelas de Participaçăo}

A definição das parcelas de participação pode sustentar-se em três bases principais: parcelas proporcionais ao salário, parcelas fixas e parcelas mistas, combinando-se proporcionalidade ao salário e valores fixos.

Neste sentido a pesquisa revela algumas alternativas: 
- as empresas que se utilizam do critério da proporcionalidade mantém e até reforçam o status do indivíduo na organização, ou seja, consideram que tanto o valor da participação quanto o salário refletem diretamente a sua contribuição nos resultados da empresa;

- aquelas que utilizam o critério de participação através de parcelas fixas consideram que o salário já realiza a distinção entre quem contribui mais ou menos para os resultados da organização, logo empregam a participação como um incentivo adicional, de maneira que o esforço seja recompensado de maneira igual para todos.

É curioso ressaltar que os dois critérios contemplam um aumento de salário real, mas no segundo caso, a proporção do aumento do salário é maior, ou seja, quando o valor da participação for igual para todos os funcionários, aqueles que possuem menores salários ganham mais.

Resultado da pesquisa SEBRAE/FIERGS/PPGA (1997) demonstra que 65,4\% das empresas, entre as que utilizam algum tipo de participação, optaram pela participação proporcional ao salário. Entretanto a análise das empresas Alpha, Beta, Gama e Delta mostra certo equilíbrio desta característica. De um lado a empresa Alpha com o critério da proporcionalidade, de outro a Gama com o critério da participação fixa e, no meio, as empresas Beta e Delta adotando os dois critérios simultaneamente.

\section{Quadro 3: Definição das Parcelas de Participação pelas Empresas Investigadas em seus Programas de Participação}

\begin{tabular}{|c|c|c|c|c|}
\hline $\begin{array}{ll}\text { EMPRESA } \\
\text { FATOR }\end{array}$ & ALPHA & BETA & GAMA & DELTA \\
\hline $\begin{array}{l}\text { CARACTERÍSTICA } \\
\text { DO VALOR DA } \\
\text { DISTRIBUIÇÃO }\end{array}$ & $\begin{array}{l}\text { Proporciona } \\
1 \text { ao salário } \\
\text { do } \\
\text { funcionário. }\end{array}$ & $\begin{array}{l}\text { Mista: } \\
70 \% \text { é proporcional } \\
\text { ao salário e } 30 \% \\
\text { igual para todos os } \\
\text { funcionários }\end{array}$ & $\begin{array}{l}\text { Igual para } \\
\text { todos os } \\
\text { funcionários }\end{array}$ & $\begin{array}{l}\text { PL: Proporcional } \\
\text { ao salário } \\
\text { PR: Igual para } \\
\text { todos os } \\
\text { funcionários }\end{array}$ \\
\hline
\end{tabular}

Em poucas palavras podemos dizer que a empresa Alpha dá maior importância à proporcionalidade da contribuição do indivíduo, a empresa Gama dá maior importância à recompensa do esforço (teoricamente igual de todos os funcionários) e as empresas Beta e Delta dão importância na conjugação destes dois fatores.

E o que pensam os empregados sobre essa questão? O resultado das entrevistas realizadas com os trabalhadores de mão de obra direta e indireta (abaixo do nível 
de supervisão) mostrou que $66,7 \%$ preferem a distribuição de um valor fixo. Era de se esperar a preferência destes trabalhadores pelo valor fixo, pois seus salários são baixos em comparação aos níveis gerenciais. Por outro lado, é interessante observar que 33,3\% dos trabalhadores, apesar de apresentarem salários mais baixos, preferem um valor proporcional ao salário. O comentário de um dos entrevistados resume uma posição de certa maneira conformada dos trabalhadores:

"O pessoal lá de cima (referindo-se à administração) estudou muito mais [...], e tem que tomar um monte de decisões muito mais importantes do que as minhas [...].Tem que cuidar de um monte de gente e conseguir agradar todo mundo ao mesmo tempo [...], por isso eles devem ganhar mais".

Na empresa Delta os funcionários têm contato com os dois tipos de participação. Neste caso, $73 \%$ dos funcionários optaram pelo valor igual para todos; segundo eles, "todos trabalham igual".

\section{Casos de Incidência/Não Incidência}

Os casos de incidência e não incidência definem dois tipo de situações:

- de inclusão ou exclusão de determinadas categorias de trabalhadores ao Plano de Participação;

- de variação no valor da distribuição para os trabalhadores que dele participam.

A questão principal é definir sobre quem e em quais circunstâncias o programa se aplica. Perguntas do tipo: O empregado ganha participação quando está de férias? E o demitido por justa causa, ganha proporcional aos meses trabalhados? E a funcionária que engravidou, ganha participação no período de licença-maternidade?

Com o objetivo de responder a estas questões tão freqüentes na rotina de qualquer empresa que utiliza este programa, considerou-se fundamental o detalhamento desta característica. Os resultados da experiência podem ser acompanhados no quadro a seguir. 


\section{QUADRO 4: Casos de Incidência/Não Incidência Definidos pelas Empresas Investigadas em seus Programas de Participação}

\begin{tabular}{|c|c|c|c|c|}
\hline $\begin{array}{l}\text { Empresa } \\
\text { Fator } \\
\end{array}$ & ALPHA & BETA & GAMA & DELTA \\
\hline $\begin{array}{c}\text { Não } \\
\text { incidência }\end{array}$ & $\begin{array}{l}\text { - Diretores e } \\
\text { estagiários. } \\
\text { - O funcionário em } \\
\text { contrato de } \\
\text { experiência se for } \\
\text { reprovado pela } \\
\text { empresa. }\end{array}$ & $\begin{array}{l}\text { - Diretores e estagiários. } \\
\text { - O empregado que sai } \\
\text { da empresa (com ou sem } \\
\text { justa causa) durante a } \\
\text { vigência do Plano. } \\
\text { - O funcionário em aviso } \\
\text { prévio, por iniciativa de } \\
\text { qualquer das partes. } \\
\text { - O funcionário em } \\
\text { contrato de experiência, } \\
\text { e todos os alunos cotistas } \\
\text { - aprendizes (Art.429 da } \\
\text { CLT). }\end{array}$ & $\begin{array}{l}\text { - Diretores e estagiários. } \\
\text { - Todo o funcionário demitido } \\
\text { durante a vigência do Plano; } \\
\text { - Não participam os aprendizes } \\
\text { do SENAI: }\end{array}$ & $\begin{array}{l}\text { - Diretores e } \\
\text { estagiários. } \\
\text { - Todo o } \\
\text { empregado que } \\
\text { sair da empresa } \\
\text { durante o } \\
\text { exercício, não } \\
\text { recebe o bônus } \\
\text { referente aquele } \\
\text { ano. }\end{array}$ \\
\hline Incidência & $\begin{array}{l}\text { - Todos os } \\
\text { funcionários da } \\
\text { empresa têm a } \\
\text { mesma chance de } \\
\text { receber } \\
\text { integralmente o } \\
\text { valor da } \\
\text { participação. } \\
\text { - Todos os } \\
\text { funcionários que } \\
\text { estiverem afastados } \\
\text { da empresa por } \\
\text { qualquer motivo, } \\
\text { (férias, faltas, } \\
\text { serviço militar, } \\
\text { doença, acidente, } \\
\text { licença } \\
\text { maternidade, etc.), } \\
\text { recebem } \\
\text { proporcionalmente } \\
\text { ao período de } \\
\text { efetivo trabalho no } \\
\text { mês em curso. } \\
\text { - O funcionário que } \\
\text { sai da empresa } \\
\text { (com ou sem justa } \\
\text { causa) tem direito a } \\
\text { receber } \\
\text { proporcionalmente } \\
\text { ao período que } \\
\text { trabalhou, mas só } \\
\text { poderá apropriar-se } \\
\text { da participação no } \\
\text { final do semestre } \\
\text { corrente. } \\
\text { - O funcionário em } \\
\text { contrato de } \\
\text { experiência assim } \\
\text { que se tornar } \\
\text { efetivo ganha } \\
\text { proporcional ao } \\
\text { tempo que } \\
\text { trabalhou. }\end{array}$ & $\begin{array}{l}\text { - Todos os funcionários } \\
\text { da empresa têm a mesma } \\
\text { chance de receber } \\
\text { integralmente o valor da } \\
\text { participação. } \\
\text { - Todos os funcionários } \\
\text { que estiverem afastados } \\
\text { da empresa, por qualquer } \\
\text { motivo (férias, serviço } \\
\text { militar, doença, acidente, } \\
\text { licença maternidade, } \\
\text { etc.), recebem } \\
\text { proporcionalmente ao } \\
\text { tempo trabalhado no } \\
\text { semestre em curso. } \\
\text { Em relação as faltas } \\
\text { adota-se o seguinte } \\
\text { critério: se o funcionário } \\
\text { tiver menos de } 2 \% \text { de } \\
\text { faltas no semestre, não é } \\
\text { aplicado nenhum redutor } \\
\text { no valor da sua } \\
\text { participação. Para } \\
\text { aqueles funcionários que } \\
\text { apresentarem mais de } \\
2 \% \text { de faltas no } \\
\text { semestre, desconta-se do } \\
\text { valor da participação, o } \\
\text { mesmo percentual de } \\
\text { faltas do funcionário. } \\
\text { A diferença resultante } \\
\text { deste cálculo é } \\
\text { distribuída somente aos } \\
\text { funcionários que } \\
\text { cumprirem o semestre } \\
\text { integralmente. } \\
\text { Todos que forem } \\
\text { empregados da empresa } \\
\text { até o último dia do } \\
\text { semestre, utilizado como } \\
\text { base no cálculo do valor } \\
\text { da participação, recebem } \\
\text { proporcionalmente ao } \\
\text { tempo trabalhado. }\end{array}$ & $\begin{array}{l}\text { - Todos os funcionários da } \\
\text { empresa têm a mesma chance de } \\
\text { receber integralmente o valor da } \\
\text { participação; } \\
\text { - Todo o funcionário que tiver } \\
\text { faltas justificadas ou não, estiver } \\
\text { em férias (afastado do trabalho), } \\
\text { possuir atrasos ou saídas } \\
\text { antecipadas ao seu horário } \\
\text { normal, recebem } \\
\text { proporcionalmente ao período } \\
\text { de efetivo trabalho no semestre } \\
\text { em curso, observando os } \\
\text { seguintes critérios: } \\
\text { 1) São descontadas da } \\
\text { participação individual do } \\
\text { funcionário na proporção de } \\
\text { uma hora perdida para cada hora } \\
\text { não trabalhada, os casos de } \\
\text { faltas justificadas por acidente } \\
\text { de trabalho, faltas legais, } \\
\text { conforme o Art. } 473 \text { da CLT, as } \\
\text { horas não trabalhadas por gozo } \\
\text { de férias e salário maternidade; } \\
\text { 2) São descontadas na } \\
\text { proporção de três horas perdidas } \\
\text { para cada uma não trabalhada, } \\
\text { os casos de faltas justificadas } \\
\text { com atestado por doença ou sem } \\
\text { justificativa, ou por não } \\
\text { cumprimento do horário do } \\
\text { expediente. } \\
\text { - Os valores decorrentes dos } \\
\text { itens } 1 \text { e } 2 \text { são creditados } \\
\text { proporcionalmente às horas } \\
\text { trabalhadas para aqueles } \\
\text { funcionários que possuírem } \\
\text { um absenteísmo inferior a } \\
\text { 1,50\% no semestre de } \\
\text { competência. } \\
\text { - Todos os aprendizes do } \\
\text { SENAI recebem a Participação } \\
\text { de forma proporcional às horas } \\
\text { de estudo no SENAI ou } \\
\text { trabalhadas na empresa; }\end{array}$ & $\begin{array}{l}\text { PL e PR: - Todos } \\
\text { os funcionários } \\
\text { da empresa têm a } \\
\text { mesma chance de } \\
\text { receber } \\
\text { integralmente o } \\
\text { valor da } \\
\text { participação; } \\
\text { PL e PR: É } \\
\text { integral para } \\
\text { todos os } \\
\text { funcionários } \\
\text { admitidos até } 31 \\
\text { de dezembro do } \\
\text { mês anterior. É } \\
\text { proporcional ao } \\
\text { número de meses } \\
\text { completos para } \\
\text { os admitidos no } \\
\text { ano corrente. } \\
\text { PL: Não tem } \\
\text { redutor, recebe } \\
\text { proporcionalment } \\
\text { e ao período } \\
\text { trabalhado } \\
\text { PR: O } \\
\text { funcionário tem } \\
\text { redutor de faltas } \\
\text { (justificadas ou } \\
\text { não): reduz em } \\
100 \% \text { o valor da } \\
\text { participação para } \\
\text { aquele } \\
\text { funcionário com } \\
\text { mais de } 3 \text { faltas, } \\
50 \% \text { de } 2 \text { a } 3 \\
\text { faltas e } 20 \%, 1 \\
\text { falta. }\end{array}$ \\
\hline
\end{tabular}


A análise nos permite concluir, que nas 4 empresas, somente estagiários e diretores são categorias não abrangidas pelo Plano de Participação. Isso demonstra que, ao menos numa primeira instância, todos os funcionários de todos os setores das empresas possuem o direito de usufruir dos benefícios do Plano. Entretanto dentro do conceito de que todos podem participar, existem exceções; cada empresa apresenta suas particularidades: excluir funcionários em contrato de experiência, ou aqueles em aviso prévio, ou ainda os demitidos durante a vigência do Plano.

Observamos que as situações de afastamentos do trabalho (férias, faltas justificadas ou não, licença maternidade, serviço militar, etc) e demissões/ contratações apresentam-se de forma mais detalhada, porque são as que mais exigem um posicionamento das empresas. Evidencia-se, desta forma, uma tendência de que elas precisam cercar-se de argumentos para explicar a filosofia predominante de que só ganha participação quem trabalha. Apesar das queixas, este espírito parece estar bem arraigado nos Planos de Participação nos Lucros ou Resultados.

Nesse sentido, notamos certa polêmica em torno das férias e das faltas por motivo de doença. Deve ou não um funcionário receber participação quando estiver no gozo de férias, ou quando não estiver em condições físicas de trabalhar? $37,7 \%$ dos entrevistados nas 4 empresas afirmaram espontaneamente que era injusto descontar os dias referentes às férias ou às faltas por motivo de doença. Dois depoimentos exemplificam bem esta situação:

$\mathrm{N}^{\mathrm{o}}$ 1: "Eu trabalho o ano inteiro, me dedico, trabalho porque gosto desta empresa [...], nunca falto [...] só faltei um dia no ano passado, quando meu pai morreu [...] então tiro 10 dias de férias e eles descontam da minha participação [...]. Assim não dá!!!!”.

$\mathrm{N}^{\mathrm{o}}$ 2: "Não faltei nenhum dia neste ano, mas na semana passada, tava com muita dor no corpo, febre e a cabeça pesada, quase sem condição de trabalhar [...] e até prejudicando aqueles que tavam bem [...], mas eu tinha que ficar pelo menos em pé, porque senão eles descontam da minha participação".

Para amenizar os impactos negativos causados pelo desconto das férias e das faltas justificadas, uma estratégia adotada pelas empresas Beta e Gama em relação aos afastamentos é ratear o valor da participação daqueles funcionários afastados, por qualquer motivo, entre os que cumprem o período integralmente. Desta 
maneira, tudo indica que as empresas podem aproveitar-se dos chamados assuntos polêmicos para criarem caminhos alternativos que comprometam ainda mais o indivíduo com o seu trabalho.

\section{Transparência}

Outra característica que apresenta uma posição de destaque nos Planos de Participação nos Lucros ou Resultados é a transparência. Esta característica pode ser explicada através da análise de três fatores:

- Acessibilidade: acesso dos funcionários aos documentos: documentos, digamos, não tão sigilosos como, por exemplo, as atas de reuniões, ou mais sigilosos como o balanço da empresa, referentes ao Plano. E liberdade de acesso dos funcionários a pessoas que possam ouvir suas dúvidas, críticas e sugestões em relação ao Programa de Participação;

- Comunicação Bilateral: comunicação em duas vias, ou seja, os tipos de instrumentos utilizados pela empresa para informar aos funcionários as regras do Plano e também os tipos de instrumentos proporcionados pela empresa para que os funcionários expressem suas opiniões em relação a estas regras. Para Fleury (1989, p.24),

"os modelos mais modernos de gestão da força de trabalho pressupõem a introdução de novos canais de comunicação entre empresa e empregado. [Estes modelos levam] mais informações aos empregados e [recebem mais] opiniões, sugestões e reivindicações, reforçando ou em certos casos procurando modificar padrões culturais".

Segundo Fleury (1993, p.33),

“a comunicação interna é um ponto muito valorizado, não só para a melhoria do clima interno, mas principalmente para obter a participação e o comprometimento dos empregados com as metas propostas".

Como se não bastasse, todos os gerentes e supervisores entrevistados foram unânimes ao afirmar que a comunicação é um aspecto inerente ao sucesso dos Planos de Participação;

- Credibilidade: a confiança dos funcionários perante as informações fornecidas pela empresa. 
O quadro a seguir apresenta as ações das empresas pesquisadas sobre o assunto:

\section{Quadro 5: Ações das Empresas para Garantir a Transparência nos Programas de Participação}

\begin{tabular}{|c|c|c|c|c|}
\hline $\begin{array}{ll} & \text { EMPRESA } \\
\text { FATOR } & \\
\end{array}$ & ALPHA & BETA & GAMA & DELTA \\
\hline TRANSPARÊNCIA & $\begin{array}{l}\text { “- É garantido a } \\
\text { todos os } \\
\text { funcionários o } \\
\text { livre acesso aos } \\
\text { documentos”. } \\
\text { - Liberdade de } \\
\text { solicitar à } \\
\text { Diretoria, } \\
\text { Supervisão ou a } \\
\text { qualquer outro } \\
\text { funcionário } \\
\text { revisão ou } \\
\text { mudanças no } \\
\text { cálculo do Plano } \\
\text { - Liberdade de } \\
\text { acesso à } \\
\text { Diretoria, } \\
\text { Supervisão ou } \\
\text { qualquer outro } \\
\text { funcionário } \\
\text { responsável pelo } \\
\text { Plano. } \\
\text { - Instrumentos } \\
\text { utilizados e } \\
\text { periodicidade: } \\
\text { Fichas (mensal), } \\
\text { Mural (mensal), } \\
\text { Boletim } \\
\text { Informativo } \\
\text { (mensal), } \\
\text { Reuniões com } \\
\text { Representantes } \\
\text { da Comissão, } \\
\text { Conversas } \\
\text { informais com } \\
\text { representantes da } \\
\text { Comissão, } \\
\text { Chefia imediata } \\
\text { ou Diretor, } \\
\text { Reuniões com } \\
\text { todos os } \\
\text { funcionários } \\
\text { (quando } \\
\text { necessário). }\end{array}$ & $\begin{array}{l}\text { “- A empresa não } \\
\text { esconde dos } \\
\text { funcionários os } \\
\text { documento sobre o } \\
\text { Plano", } \\
\text { - Liberdade de acesso à } \\
\text { Gerência, Supervisão } \\
\text { ou qualquer outro } \\
\text { funcionário } \\
\text { responsável pelo } \\
\text { Plano. } \\
\text { Os instrumentos } \\
\text { utilizados para a } \\
\text { divulgação são: Jornal } \\
\text { da Empresa (mensal) e } \\
\text { Mural (mensal). } \\
\text { Existem } 3 \text { momentos } \\
\text { de comunicação: } \\
\text { - sobre o andamento do } \\
\text { Programa: Reuniões } \\
\text { com periodicidade } \\
\text { semanal entre os } \\
\text { supervisores; } \\
\text { - sobre os resultados do } \\
\text { Programa: Reuniões } \\
\text { com periodicidade } \\
\text { mensal para os } \\
\text { funcionários. Reunião } \\
\text { mensal "informal” } \\
\text { entre os supervisores. } \\
\text { Reunião mensal com } \\
\text { os acionistas; } \\
\text { - sobre a estrutura do } \\
\text { Programa: A } \\
\text { periodicidade é } \\
\text { definida pela mudança } \\
\text { na estrutura do } \\
\text { Programa. Reuniões } \\
\text { com todos os } \\
\text { funcionários e com } \\
\text { acionistas. }\end{array}$ & $\begin{array}{l}\text { - Somente a Comissão } \\
\text { de Negociação tem } \\
\text { acesso aos documentos } \\
\text { referentes ao cálculo da } \\
\text { Participação dos } \\
\text { Resultados. } \\
\text { - Somente a Comissão } \\
\text { de Negociação tem } \\
\text { liberdade de solicitar à } \\
\text { Diretoria, Supervisão ou } \\
\text { a qualquer outro } \\
\text { funcionário, revisão ou } \\
\text { mudança no cálculo do } \\
\text { Plano. } \\
\text { - Liberdade de acesso à } \\
\text { Diretoria, Supervisão ou } \\
\text { qualquer outro } \\
\text { funcionário responsável } \\
\text { pelo Plano. } \\
\text { Os instrumentos } \\
\text { utilizados para a } \\
\text { divulgação são: Jornal } \\
\text { Interno, (mensal) e } \\
\text { Murais (mensal) e } \\
\text { Rádio Interno, Reuniões } \\
\text { com a Supervisão } \\
\text { (sempre que necessário) } \\
\text { e Caixa de Sugestões } \\
\text { - Mensalmente a } \\
\text { Comissão se reúne para } \\
\text { apreciar os resultados } \\
\text { antes de divulgá-los aos } \\
\text { funcionários. } \\
\text { “- Todos os } \\
\text { funcionários são } \\
\text { responsáveis pela } \\
\text { divulgação dos } \\
\text { resultados. } \\
\text { Formalmente as chefias } \\
\text { são as principais } \\
\text { responsáveis.” }\end{array}$ & $\begin{array}{l}\text { “A empresa } \\
\text { coloca os } \\
\text { documentos a } \\
\text { disposição de } \\
\text { todos os } \\
\text { funcionários.” } \\
\text { - Liberdade de } \\
\text { acesso à } \\
\text { Diretoria, } \\
\text { Supervisão ou } \\
\text { qualquer outro } \\
\text { funcionário } \\
\text { responsável pelo } \\
\text { Plano. } \\
\text { Os instrumentos } \\
\text { utilizados para a } \\
\text { divulgação são: } \\
\text { Jornal Interno, } \\
\text { (mensal) e } \\
\text { Murais (mensal) } \\
\text { e Reuniões com } \\
\text { a Gerência e } \\
\text { Supervisão } \\
\text { (sempre que } \\
\text { necessário) }\end{array}$ \\
\hline
\end{tabular}

Com relação à acessibilidade aos documentos, notamos que as empresas Alpha, Beta e Delta permitem a todos os empregados interessados o acesso aos documen- 
tos referentes ao Plano; já na empresa Gama somente os membros da Comissão de Negociação (formada por 4 membros eleitos pelos funcionários e 4 designados pela empresa) têm acesso a estes documentos.

Mas de que adianta a permissão de acessibilidade, se não houver liberdade de aproximação às pessoas que possuem certa ingerência sobre o Plano? Quanto a esta questão, podemos ficar tranqüilos, pois a pesquisa realizada com os funcionários demonstra que $95 \%$ dos entrevistados se sente a vontade para reivindicar ou esclarecer suas dúvidas sobre o Plano. E $85,7 \%$ afirmaram que utilizam a chefia direta e a supervisão para isso.

Os instrumentos mais utilizados para a comunicação são: mural, jornal interno e reuniões. Constata-se que tanto o mural quanto o jornal interno são formas de comunicação unilateral. Já as reuniões, amplamente utilizadas, permitem de fato uma comunicação bilateral, mas uma queixa percebida é que expõem os funcionários. Formas bilaterais de comunicação, que preservam o funcionário, são ainda pouco utilizadas, como é o caso da caixa de sugestões, observada em apenas uma empresa.

Um ponto relevante para avaliar a eficiência da comunicação nas empresas foi a confrontação entre os objetivos do Plano apresentados pela empresa e os objetivos do Plano para os funcionários. Após apresentar a mesma lista com os motivos que levaram a empresa a adotar o Plano para a gerência e para os trabalhadores, surpreendentemente podemos dizer que apenas a empresa Delta apresentava sintonia entre os objetivos escolhidos por cada uma das partes.

Em termos do conteúdo da comunicação, cabe verificar se a informação que a empresa transmite aos funcionários contém aquilo que estes últimos esperam. Neste sentido, as entrevistas com dois funcionários são bastante expressivas:

$\mathrm{N}^{\mathrm{o}} 1$ :"Eles vêm aqui uma vez por mês e colocam um monte de coisa aqui no quadro (mural) [...]. Todo mundo olha, faz cara de entendido [...] e sai. Mas conversando por aí nós vemo que o que interessa mesmo pro pessoal é só o lucro, né [...]".

$\mathrm{N}^{\mathrm{o}}$ 2: "Nós não entendemo [...] esse quadro sempre tá cheio de número [...], mas o que o pessoal qué sabê mesmo é o que vai vim no fim $[\ldots]$ o que vai sobrá pra nós $[\ldots] "$ ".

Analisando esses comentários, observa-se que, para uma categoria de funcionários, a empresa difunde um excesso de informações. Mas é importante destacar a 
diferença entre informações sobre as regras do Plano e as informações periódicas de andamento do Plano. Os depoimentos demonstram que os empregados desejam saber periodicamente os dados simples e diretos tais como Lucro ou Faturamento, Custos Totais e acima de tudo informações sobre o valor acumulado de participação até o momento. Nesta questão todo o cuidado é pouco. O recomendável é que a empresa negocie com os funcionários as informações que mais interessam, para que depois não seja considerada omissa.

Quanto à credibilidade, as respostas dos empregados em face da questão "Você acredita que a empresa cumpre o que promete?" mostra que $85 \%$ dos entrevistados concordaram que a empresa sempre cumpria com o que prometia. Já em relação a questão "Você acredita que os valores referentes ao lucro da empresa são verdadeiros?", 71,4\% dos entrevistados entendem que as informações da empresa são corretas. Embora nas respostas a essas duas questões esteja expresso um nível bastante razoável de credibilidade e segurança dos funcionários em relação aos Planos da empresa, não há como negar que a existência de dúvidas acerca da "verdadeira" situação de lucratividade da empresa, entre 28,6\% dos funcionários, deve ser olhada com bastante atenção.

Uma análise individual por empresa revela que a empresa Gama foi a responsável pela diminuição desses percentuais, uma vez que na primeira questão, 33,3\% dos funcionários tendiam a não acreditar nas promessas da empresa e na segunda questão nada menos que 53,3\% não consideraram verdadeiras as informações referentes ao lucro da empresa. A maioria dos funcionários da empresa Gama tinha este tipo de opinão:

" não acredito que uma empresa deste tamanho, que vende tudo aquilo que a gente produz tenha só aquilo de lucro [...] alguma coisa tá errada. Se ela não vendesse, [...] aí tudo bem [...], mas pelo contrário. Pode olhar aí no pátio, não tem nada. O que ela faz com o dinheiro que recebe ninguém sabe, ninguém viu $[\ldots] "$.

Um balanço sobre a característica transparência, permite observar que, em geral, as empresas consideram esse fator essencial para o comprometimento dos funcionários. Soluções criativas do tipo APG's - Atividades em Pequenos Grupos, Team Briefing, Diálogo (Becker e Conrado, 1996), podem ser alternativas que estimulem a integração dos empregados com os objetivos dos Programas de Participação. Entretanto as observações desenvolvidas acima permitem concluir que as estratégias para a transparência utilizadas pelas empresas, principalmente em relação à comunicação, ainda deixam a desejar. 


\section{Envolvimento do Funcionário}

Nossa última característica diz respeito ao envolvimento do funcionário com o Plano de Participação. Além de informar se houve interferência do empregado na elaboração e no desenvolvimento do Plano, um dos objetivos deste item é identificar quais ações as empresas têm desenvolvido para estimular a participação do funcionário no programa.

Os resultados demonstram que nenhuma empresa da amostra pesquisada teve a intenção de envolver o funcionário na fase de elaboração do Plano, decidindo unilateralmente questões sobre a estrutura do programa, suas regras e indicadores. O Gerente de Recursos Humanos da empresa Beta colocou o seguinte argumento que representa também a opinião dos demais executivos entrevistados:

"Devido ao ineditismo desta nova estratégia de gestão, os funcionários mostraram-se inseguros e incapazes de contribuírem com idéias [...] pois eles não tinham o conhecimento necessário sobre o assunto".

É curioso observar que, apesar dessas opiniões, a empresa Delta tem negociado algumas das regras de seu Plano com o sindicato das categorias dos trabalhadores.

Nas fases seguintes à construção do Plano, as empresas Alpha, Beta e Gama perceberam a necessidade de negociar determinados parâmetros com os funcionários, evitando desta forma exigências mal dimensionadas e, conseqüentemente, desestimulantes para os funcionários. Buscando esta integração, as empresas Alpha e Gama formaram Comissões de Negociação, constituídas por representantes das duas partes. Os representantes dos trabalhadores foram eleitos por votação direta entre todos os funcionários.

A empresa Beta não formalizou a existência de uma Comissão de Negociação, afirmando que "a verdadeira Comissão compreende todos os funcionários da empresa". Entretanto percebendo que a criação de um instrumento que permitisse ao trabalhador monitorar os custos da empresa implicaria maior envolvimento geral, implantou-se recentemente o sistema da Planilha de Custos. Esta Planilha é enviada para todos os setores da empresa e é preenchida mensalmente por cada um deles. A intenção é que a Planilha mostre para o funcionário os custos de seu setor, e lhe dê a oportunidade de gerenciá-los diretamente. Aproximando o trabalhador desta informação e fornecendo-lhe este tipo de controle, a empresa está 
confiante no atingimento de um maior envolvimento e comprometimento do trabalhador com o programa.

O quadro abaixo resume o caso das empresas pesquisadas.

\section{Quadro 6: Ações das empresas para garantir o Envolvimento do Trabalhador nos Programas de Participação}

\begin{tabular}{|c|l|l|l|l|}
\hline \multicolumn{1}{|c|}{ EMPRESA } & \multicolumn{1}{|c|}{ ALPHA } & \multicolumn{1}{c|}{ BETA } & \multicolumn{1}{c|}{ GAMA } & DELTA \\
\hline $\begin{array}{c}\text { FATOR } \\
\text { ENVOLVIMENTO } \\
\text { DO }\end{array}$ & $\begin{array}{l}\text { - Negociação das } \\
\text { regras com a } \\
\text { Comissão dos } \\
\text { Funcionários }\end{array}$ & $\begin{array}{l}\text { Planilha de } \\
\text { Custos que } \\
\text { possibilitará ao } \\
\text { próprio setor o } \\
\text { monitoramento e } \\
\text { gerenciamento de } \\
\text { seus gastos. }\end{array}$ & $\begin{array}{l}\text { Negociação, acordo } \\
\text { com a Comissão }\end{array}$ & $\begin{array}{l}\text { Praticamente } \\
\text { nenhum. } \\
\text { Negociação das } \\
\text { regras diretamente } \\
\text { com o sindicato. }\end{array}$ \\
\hline
\end{tabular}

\section{ComentáRios Finais}

Temas que se caracterizam por um debate ainda incipiente, como a questão que tratamos acerca das políticas de participação em lucros ou resultados, exigem um tratamento muito cuidadoso, especialmente quando se pretende construir algumas considerações finais de uma pesquisa empírica. Mesmo assim, os resultados de nossa investigação permitem identificar alguns aspectos mais sistemáticos, algumas tendências que merecem um destaque particular.

Em primeiro lugar, no que concerne à decisão da referência usada como base do Programa de Participação, se lucros ou resultados, observamos que, apesar da controvérsia no debate, tem prevalecido a opção pelos sistemas com base em Resultados e uma tendência à adoção de sistemas mistos, a fim de evitar premiações por resultados em situações de margens de lucro consideradas abaixo do previsto. Essa constatação é confirmada pelo caso das empresas investigadas em nossa pesquisa.

Quanto à definição dos montantes das parcelas de participação, observou-se em pesquisa com 150 empresas industriais do RS, que dentre aquelas que aplicam esse tipo de programa, 65,4\% optaram por parcelas de participação proporcionais ao salário. Já entre os trabalhadores, há clara predominância dos que preferem parcelas baseadas em valores fixos, tendo em vista, segundo eles, os valores salariais relativamente baixos. 
Nas quatro empresas investigadas, os Programas de Participação pretendem incidir sobre todos os funcionários, excetuando os Diretores e estagiários. Observou-se também, entre elas, um esforço de comunicação no sentido de fazer valer o princípio da transparência. Paradoxalmente, porém, o conjunto de informações repassadas parece, em alguns casos, ser excessivo para o nível de compreensão de parte dos trabalhadores, como confirmaram os resultados das entrevistas dentre eles.

Observou-se, também, nas empresas pesquisadas, que não houve envolvimento dos funcionários na concepção do Plano, o que, considerada a questão da relação Programa de Participação e Estratégia de Comprometimento, levanta dúvidas sobre a clareza das empresas quanto a esse tipo de iniciativa.

Finalmente, as pesquisas realizadas confirmam que esses Programas de Participação se encontram ainda em fase de experimentação em grande parte das empresas brasileiras e, por isso mesmo, não apresentam ainda definições muito claras do que deve ser feito e quais alternativas devem ser adotadas. Aliás, essas dúvidas também perpassam o meio sindical e grande parte dos trabalhadores, os quais, salvo raras exceções, pouco têm contribuído nessas definições. O que parece definitivo é a importância desse tipo de programa no contexto da nova configuração de gestão do trabalho e das necessidades, daí resultantes, de comprometimento e envolvimento dos trabalhadores. Ao que parece esses programas vieram para ficar.

\section{NOTAS}

\footnotetext{
${ }^{1}$ Pesquisa realizada entre final de 1996 e início de 1997, em 150 empresas industriais do Rio Grande do Sul, com o objetivo de avaliar o estágio de inovação nas formas de gestão e o nível de competitividade através do uso de Indicadores de Qualidade e Produtividade.

${ }^{2}$ Pesquisa publicada pelo Jornal Zero Hora, promovida pela FIERGS em 131 indústrias gaúchas no final do ano de 1994.

${ }^{3}$ Pesquisa PLR UP DATE: as respostas do Mercado à Regulamentação da Participação nos Lucros ou Resultados, realizada em 1996, com base em 150 acordos/convenções sobre o tema em exame no Brasil.

${ }^{4}$ Pesquisa PRL UP DATE (1996) revela que dos 150 acordos desse tipo de Programa de Participação investigados, $17 \%$ estão associados à participação nos lucros, 53 \% à participações nos resultados e $18 \%$ à forma mista, ou seja, utilizam os dois tipos de participação.
} 


\section{ReferênCIAS Biblográficas}

BECKER, G.;

CONRADO, D.

Novas formas de gestão de recursos humanos como resultado do programa de qualidade na Empresa X. In : XX ENCONTRO ANUAL DA ANPAD (1996 : Rio de Janeiro). Anais ... Rio de Janeiro : ANPAD, 1996.

\section{CHIAVENATO, I.}

Gerenciando pessoas : o passo decisivo para a administração participativa. São Paulo : Makron Books, 1994.

\section{COOPERS;}

LYBRAND.

Remuneração estratégica : a nova vantagem competitiva. São Paulo : Atlas, 1996.

DAVIS, K.;

NEWSTROM, J. W.

Comportamento humano no trabalho. São Paulo : Pioneira, 1992.

FLEURY, M. T. L.

O desvendar da cultura de uma organização - uma discussão metodológica. In : FLEURY, M. T. L.; FISCHER, R. M. Cultura e poder nas organizações. São Paulo : Atlas, 1989.
Cultura da qualidade e mudança organizacional. Revista de Administração de Empresas, mar./abr. 1993.

MEDIDA PROVISÓRIA n. 153930, de 11 de abril de 1997.

REVISTA COMÉRCIO E CONSUMO.

Participação nos lucros gera parceria. Porto Alegre : jul. 1995. p.38-40.

RUAS, R. L.

Novos princípios gerenciais e a organização e gestão do trabalho. Caderno Técnico Reestruturação Produtiva no Brasil - CNI/SESI, 1995.

SEBRAE/FIERGS/PPGA.

Pesquisa sobre indicadores de qualidade e produtividade.

Porto Alegre, 1997. (Mimeo).

ZERO HORA.

Medida estimula negociação. Porto Alegre: FIERGS, jan. 1994.

ZYLBERSTAJN, H.

Pesquisa UP DATE. São Paulo, 1996. (Mimeo). 